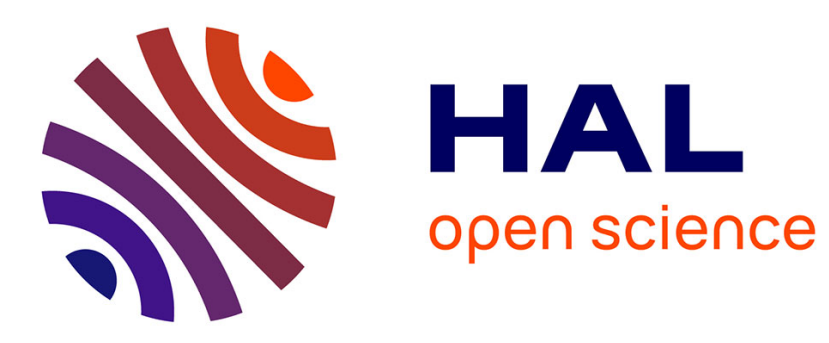

\title{
Visualization of Interactions Between Product and Service Lifecycle Management
}

Ingo Westphal, Mike Freitag, Klaus-Dieter Thoben

\section{To cite this version:}

Ingo Westphal, Mike Freitag, Klaus-Dieter Thoben. Visualization of Interactions Between Product and Service Lifecycle Management. IFIP International Conference on Advances in Production Management Systems (APMS), Sep 2015, Tokyo, Japan. pp.575-582, 10.1007/978-3-319-22759-7_66 . hal-01431147

\section{HAL Id: hal-01431147 \\ https://hal.inria.fr/hal-01431147}

Submitted on 10 Jan 2017

HAL is a multi-disciplinary open access archive for the deposit and dissemination of scientific research documents, whether they are published or not. The documents may come from teaching and research institutions in France or abroad, or from public or private research centers.
L'archive ouverte pluridisciplinaire HAL, est destinée au dépôt et à la diffusion de documents scientifiques de niveau recherche, publiés ou non, émanant des établissements d'enseignement et de recherche français ou étrangers, des laboratoires publics ou privés. 


\title{
Visualization of interactions between Product and Service Lifecycle Management
}

\author{
Ingo Westphal ${ }^{1}$, Mike Freitag $^{2}$, Klaus-Dieter Thoben ${ }^{1}$ \\ ${ }^{1}$ BIBA - Bremer Institut für Produktion und Logistik GmbH at the University of Bremen \\ Hochschulring 20, 28359 Bremen, Germany \\ wiedbiba. uni-bremen. de \\ ${ }^{2}$ Fraunhofer Institut für Arbeitswirtschaft und Organisation \\ Nobelstraße 12, 70569 Stuttgart, Germany \\ mike.freitag@iao.fraunhofer. de
}

\begin{abstract}
The adoption of advanced manufacturing intelligence technologies offers opportunities for new profitable business models. The basis for this is the data that is related to the manufactured product, the physical components used for the manufacturing and the services that are applied in this context. In such a Product-Service System (PSS) there are several interactions and corresponding dependencies between physical products and services that have to be managed to obtain an optimal added value from the PSS. A first step is to make the informational interactions between Product and Service Lifecycle Management (PLM and SLM) transparent and visualize them. The objective of this paper is therefore to identify and visualize the interactions between SLM and PLM in general and as a subsequent step in a use case of a manufacturing enterprise.
\end{abstract}

Keywords: Product Service Systems, Lifecycle Management, Service Science, Service Engineering, Servitization.

\section{Introduction}

Manufacturing enterprises realize that services, in particular services that are built upon data generated along the product lifecycle and make use of the internet, become more and more important and provide new opportunities for revenues and growth.

However, many small and medium size enterprises (SME) in the manufacturing sector do not have a clear picture regarding the opportunities of combining such services with their products and are uncertain about the effects on their core business and their corresponding processes. So the objective of this paper is to support such enterprises to obtain a better understanding of those effects. It suggests a methodical approach to identify and visualize the interactions between SLM and PLM.

The combination of physical products and corresponding services is established for many years with growing importance $[1,3,4,7,8,9,10]$. While initial approaches were product-centered, in the course of time the services became a more important 
and self-reliant part of the product-service combination. In some cases the physical product was even aligned to a service or parts of it were replaced by services, e.g. cloud services that replace hardware storage capacity. The approach of Product Service System represents this development [5, 6].

Goedkoop et al defined that a PSS is "a marketable set of products and services capable of jointly fulfilling a user's need" and that it can be "provided by either a single company or by an alliance of companies". They pronounce that products and services can be equally important for the function fulfilment.

Although the concepts of product-service combinations are discussed in literature from different points of view, e.g. the different types of added value provided by the PSS [5, 11], the dependencies and interactions between the product and the service along their lifecycles are still not covered sufficiently. But these dependencies and interactions are relevant for SME when they have to decide if and how they are going to servitize their business. According to the objectives mentioned above this paper is going to fill a part of this gap.

\section{Product and Service Lifecycle Management}

Approaches like the Extended Product approach have shown that different services can be applied at different points of a product's lifecycle [3].

Therefore the concepts of Product Lifecycle Management (PLM) and Service Lifecycle Management (SLM) can be used as a framework for considerations regarding the dependencies and interactions between products and services in a PSS. The main objective of PLM and SLM is to provide a sound information basis to plan, control and coordinate processes and take decisions along the lifecycles of products and services. A holistic view of both PLM and SLM is necessary to involve all relevant aspects of the enterprise for an integrated development and management of PSS $[8,12,13]$.

There are different concepts for Product Lifecycles and Product Lifecycle Management, for example concepts that are marketing driven and consider phases like development/introduction, growth, maturity and decline [14]. Since it aiming at a better understanding of PSS this paper focuses on PLM concept that take the view of information management. Many of those approaches structure the lifecycles in the main phases Beginning of Life (BOL), Middle of Life (MOL) and End of Life (EOL) with corresponding sub-phases as described in the following list $[15,16,17]$ :

- Beginning of Life: Product Ideation, Design/Engineering, Realization/Production/Manufacturing and Logistics/Distribution.

- Middle of Life: Use and Maintenance/Service/Support.

- End of Life: Re-use, Recycling, Remanufacturing, and Disposal.

Most traditional approaches assume that phases and steps in the lifecycle are connected in a sequential mono-directional manner, a waterfall cascading model.

However, in dynamic environments there could be loops, parallelism and multidirectional processes. The digitalization of all the PLM phases enables and fosters this 
development. That's why more recent approaches have recognized such loops and multidirectional processes, e.g. the Closed Loop PLM [18]. On the one hand this provides flexibility for the interactions with SLM on the other hand it increases complexity.

Service Lifecycle Management is a part of Service Science, Management and Engineering (SSME), which address the challenges coming from the servitization process $[1,9,13]$. SSME provides useful input for the manufacturing industry and helps to involve all the relevant aspects of service. A Service Lifecycle Management creates a connection between Management and Engineering and is an important discipline for providing and contributing specific knowledge about service. The three main phases of the Service Lifecycle are service creation, service engineering and service operations management. These three main phases are divided in 7 sub phases [19]:

- Service creation: Service Ideation.

- Service Engineering: Service Requirement Analysis, Design, Implementation, and Testing.

- Service Operation: Service Delivery and Evolution.

For a PSS lifecycles of products and services are linked and, as a consequence, the lifecycle managements have to be aligned to those links or even integrated.

\section{Relations and between Products and Services in a PSS}

Products and services are related in different ways. Before these relation can be made transparent and can be planned, controlled and coordinated in a Lifecycle Management process, it has to be clarified what types of relations can generally occur in PSS. This describes a kind of solutions space that has to be covered by the Lifecycle Management. To define these types a literature research was done and existing concepts were analyzed according to the offered classifications of relations between products and services in a PSS.

There are already approaches considering the configuration of defined product and service component. Becker and Klinger [20] gave an overview of concepts and methods in this context. They summarize three main types of relations when it comes to the configuration of product-service combination: proposing, restricting and modifying. A product provides options for combinations with a set of potential services or vice versa. This is described as proposing options and alternatives. E.g. a Smart-TV is supported be a set of capable TVs from different producers. It is also possible that it is proposed that some product functions are substituted by services and or services are substituted by the product. The second type are restricting relations. They describe what prerequisites a service (product) has to fulfil when it should be combined with a certain product (or service) or characteristics of a service (or product) exclude it from such a combination. E.g. if the service addresses mainly food-industry, products that do not fulfil the corresponding hygienic requirements are excluded.

Services can modify characteristics of the products or vice versa when they are combined. E.g. the value that a product provides to its customer is increased by the services. These three types represent functional relations. 
Other approaches, like the Extended Product of Thoben [3], consider the different points in the lifecycles of products and services when there are relations between them. For example consulting services during the specification of a product in its BOL phase or refurbishing service in the EOL phase. Another more simple differentiation is that between pre-sales and after-sales like it used in many enterprises. Generally these relations cover the logical sequence of activities regarding the products and services. In many cases one activity provides material or informational input to another, e.g. the configuration services offers data from a social media feedback service and provides input for manufacturing of the product like a customized computer. This type can be describe process- and information-related relations.

An important aspects of PSS that is covered by many authors [11, 21, 22] are the business models (BM) for the PSS. Tucker for example differentiate between productoriented BM where the products are sold, use-oriented BM where products are leased or rented and result-oriented BM where the customers pays for the obtained value, e.g. the achieved output of a machine. In the result oriented BM the customer pays only for the service, he does not have to care of the price of the product as such, e.g. the price of the machine. So the product has to be pay "internally in the PSS" by the revenues generated through the service. So a further type of relations can be described as economic relations.

Many approaches assume that PSS are provided by collaborating enterprise networks $[6,21]$. The implication is there is an organizational aspect of PSS. If product and service components are provided by different partners there are organizational relations between them. Some authors $[5,6,21]$ pointed out that such relations between products and service become already relevant inside enterprises when product and service department are traditionally separated and the PSS approach requires change processes and a shift of culture. A special aspect in this context is the involvement of customers that is usually required for service delivery.

So, summarized, literature research and analysis brought up four main types of relations between products and services in a PSS along the lifecycles:

- Functional relations

- Process- and information-related relations

- Economic relations

- Organizational relations

\section{$4 \quad$ Making interactions between Products and Services transparent}

The relations identified above are not just descriptive but require in most cases some actions. Since relations connect different elements these actions are usually interactions. Interactions can be defined as reciprocal micro-processes between partners that are elementary for the accomplishment of the tasks in the processes [23]. Following typical interactions can be relevant between PLM and SLM: 
- Exchange of Information (e.g. information about available sensor data that can be used for a digital service).

- Coordination (e.g. synchronizing the change management for service with product development).

- Solving conflicts (e.g. identifying in-compatibilities at data interface and defining common standards).

- Negotiation (e.g. if parameters like the frequency of measurement does not fit together and adaptions have to be made on both sides to make product and service work together).

The different characteristics of products and services, e.g. regarding timespans in the lifecycles, the variety of potential combinations, and collaboration between partners in a network lead to a high complexity of PSS. One element of handling and, where possible, reducing this complexity is to manage these interactions for all four types of relations between products and services. Conventional approaches to consider and design those relations, such as a simple flowcharts, do not meet the specific requirements of this complexity satisfactorily. Typical problems are [24] that recorded relationships between tasks are simplified, relationships are ignored, iterations cannot be reflect adequately or that „,coupled“" activities are not representable.

Starting Point for the making relations between products and services visible should be the process- and information related relations, since these relations cover the whole lifecycles right from the early BOL till the EOL and provide the basis for the other relations. In addition this type of relation is causing manifold unplanned iterations and corresponding problems [24], e.g. information is provided at the wrong time or not suitable, modifications cause changes in the assumptions and data, inadvertently erroneous information or unrecognized false assumptions adopted for granted.

Although a flowchart has clear limitations it is useful to visualize the general process- and information-related relations. In

Figure 1 it can be seen at first sight where most interactions take place. In this practical example the prevailing strong interaction between product design and service design is obvious.

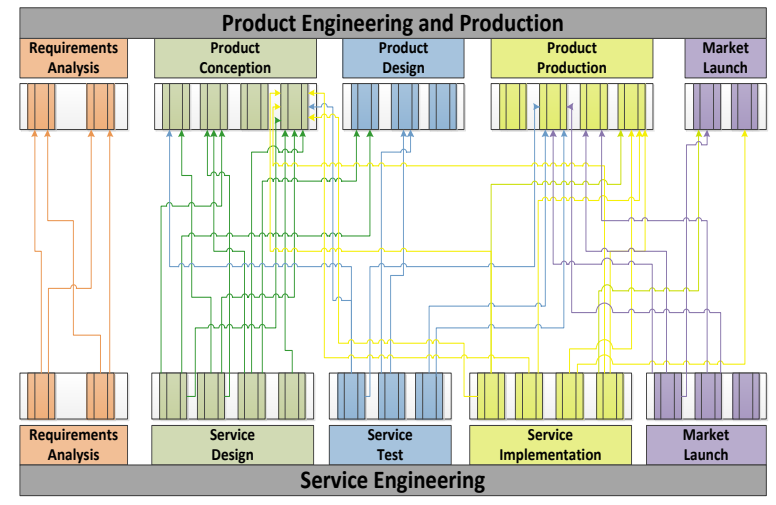


Figure 1. Use case - Manufacturing Company [6]

Therefore, it is useful to consider this phase separately and create in a next step a Design Structure Matrix for it. Figure 2 is an example of this.

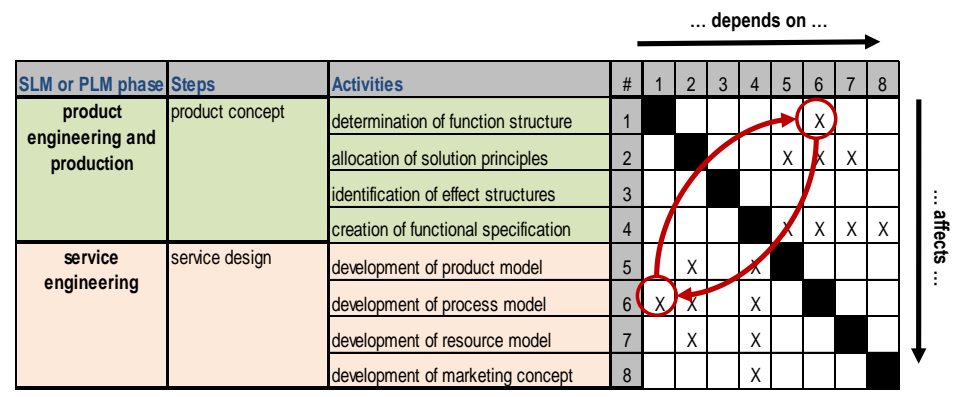

Figure 2. Design Structure Matrix - Use Case

In this example the determination of the product's function structure requires information regarding the process model for the services and the development of this process has to be aligned to the functions of the product. The reason for this informationrelated relation is another type of relation: functional relations.

This leads to general methodical pattern: Functional relations could have an impact on process- and information-related relations, so they have to be checked when processand information-related relations are assessed.

The relations in the design structure matrix describe what has to be exchanged, coordinated, solved and negotiated. The next step is the question who should do that. Does the enterprise have the capabilities and capacities to do the process step on its own or is it necessary to involve capable partners. In this way the process- and informationrelated relations lead to organizational relationships.

The final type of relations, the economic relation, usually depend on organizational relation. If different partners are involved in the development and provision of product and service function it has to be managed how investments/costs and benefits are shared. In addition the functional relations provide the basis of revenues since the represent the value the customers pays for.

The following graphic gives an overview over these relations and shows that there also can be loops of adaptations, e.g. when functional relation are simplified because it is recognized if the organizational interactions become too complex to manage.

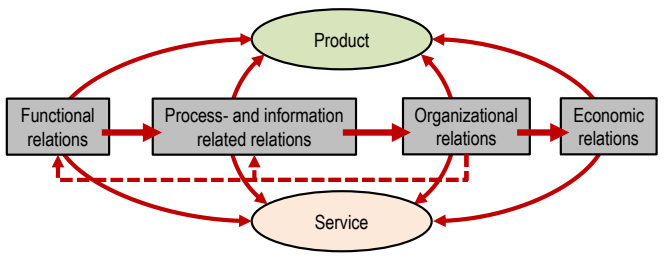

Figure 3. Relations and their dependencies in a PSS 
When these relations are generally identified the can be described in more detail according to the typical interactions (information exchange, coordination etc.).

\section{Summary}

Manufacturing enterprises that plan to servitize towards PSS need a sound understanding what effects the combination of their products with services has upon those products and upon their processes. This paper suggests an approach to make the potential relation and corresponding interactions between products and services transparent and to analyze them. Based on existing PSS approaches it has identified four general types of relations between product and service in a PSS: functional, processand information related, organizational and economic. Between these types of relations there a dependencies that help to structure a step-wise analysis. The application on a use-case have shown that this approach could to clarify the complex relations and interaction in a PSS. This approach could contribute to the further development of an integrated PSS lifecycle management.

\section{Acknowledgements}

This work has been partly funded by the European Commission through the FoF-ICT Project MSEE: Manufacturing Service Ecosystem (No. 284860) and PSYMBIOSYS (No. 636804). The authors wish to acknowledge the Commission and all the project partners for their contribution.

\section{References}

1. Wiesner S., Freitag M., Westphal I., Thoben K.-D. (2015): Interactions between Service and Product Lifecycle Management. In Proceedings of the $7^{\text {th }}$ CIRP Industrial ProductService Systems (IPS2) Conference, St. Etienne, France.

2. Acatech (2011): Cyber-Physical Systems: Innovationsmotor für Mobilität, Gesundheit, Energie und Produktion, acatech Position.

3. Thoben, Klaus-Dieter; Eschenbächer, Jens; Jagdev, Harinder: Extended Products: Evolving Traditional Product Concepts. Proceedings of the 7th International Conference on Concurrent Enterprising 27 - 29 June, Bremen, 2001

4. Meier, I. H. (2012). Hybride Leistungsbündel-ein neues Produktverständnis. In Integrierte Industrielle Sach-und Dienstleistungen (pp. 1-21). Springer Berlin Heidelberg.S

5. Goedkoop, Mark J.; van Halen, Cees J.G.; te Riele, Harry R.M.; Rommens, Peter J.M. (1999): Product Service systems, Ecological and Economic Basics.

6. Mont, Oksana K. (2002): Clarifying the concept of product-service system. Journal of cleaner production 10.3 , pp. 237-245.

7. Vandermerwe S., Rada J.: Servitization of business: adding value by adding services. European Management Journal, pp. 314-324, (1988)

8. Wiesner S., Guglielmina C., Gusmeroli S., Dougmeingts G. (Eds.): Manufacturing Service Ecosystem. Mainz Verlag: Aachen (2014) 
9. Spohrer J., Maglio P. (2010): Toward a Science of Service Systems. In: Kieliszewski, Maglio P, Spohrer J. Handbook of service science. Springer, pp. 157-194, New York.

10. Freitag M. (2014): Konfigurierbares Vorgehensmodell für die exportorientierte Entwicklung von technischen Dienstleistungen. Dissertation, Fraunhofer Verlag, Stuttgart.

11. Tukker, Arnold (2004): Eight types of product-service system: eight ways to sustainability? Experiences from SusProNet. In: Business strategy and the environment 13.4, pp. 246260.

12. Freitag M., Ganz W. (2011): InnoScore ${ }^{\circledR}$ service. Evaluating innovation for productrelated services. In: Service Research \& Innovation Institute (Eds): Annual SRII global conference (SRII) San Jose, California, USA ; proceedings, IEEE, Piscataway, NJ, pp. 214-221.

13. Spath D., Fähnrich K.-P., Freitag M., Meyer K. (2010): Service Engineering internationaler Dienstleistungen. Stuttgart, Fraunhofer Verlag.

14. Levitt, T.: Exploit the Product Life Cycle, http://hbr.org/1965/11/exploit-theproductlifecycle/ar/1

15. Ranasinghe, D.C., Harrison, M., Främling, K., McFarlane, D. (2011): Enabling through life product- instance management: Solutions and challenges. J. Netw. Comput. Appl. 34(3), 1015-1031.

16. Kiritsis, D. (2011): Closed-loop PLM for intelligent products in the era of the Internet of things. Comput.-Aided Des. 43(5), 479-501.

17. Stark, J. (2011): Product Lifecycle Management: 21st Century Paradigm for Product Realisation. Springer.

18. Hong-Bae, J., Kiritsis, D., \& Xirouchakis, P. (2007): Research Issues on Closed-loop PLM. Computers in Industry, 58(8-9), pp. 855-868

19. Freitag M.: Service Engineering and Lifecycle Management for IT-Services. In: Wiesner S., Guglielmina C., Gusmeroli S., Dougmeingts G. (Eds.): Manufacturing Service Ecosystem. pp. 33-40, Mainz Verlag: Aachen (2014)

20. Becker, Michael; Klingner, Stephan (2013): Formale Modellierung von Komponenten und Abhängigkeiten zur Konfiguration von Product-Service-Systems. In: Thomas, Oliver; Nüttgens, Markus (edts.): Dienstleistungsmodellierung 2012 - Product-Service Systems und Produktivität. Springer, Wiesbaden.

21. Baines, T. S.; Lightfoot, H. W.; Evans, S.; Neely, A.; Greenough, R.; Peppard, J.; ... \& Wilson, H. (2007): State-of-the-art in product-service systems. In: Proceedings of the Institution of Mechanical Engineers, Part B: Journal of Engineering Manufacture, 221(10), 1543-1552.

22. Andersen, Jakob Bejbro; McAloone, Tim C.; i Mateu, Adrià Garcia; Mougaard, Krestine; Neugebauer, Line; Hsuan, Juliana; Ahm, Thorkild (2013): PSS Business Models -A workbook in the PROTEUS Series. Technical University of Denmark (DTU), Kongens Lyngby.

23. Weber, F. (2007): Formale Interaktionsanalyse: Ein Beitrag zur systematischen Gestaltung von Informations- und Kommunikationsstrukturen im Concurrent Enterprise durch die Berücksichtigung von Informationseigenschaften. Universität Bremen.

24. Eppinger S. (2002): Managing complex system development projects, MIT Press, Cambridge.

25. Penzenstadler B., Eckhardt J. (2012): A requirements engineering content model for cyberphysical systems. In Requirements Engineering for Systems, Services and Systems-ofSystems (RES4). IEEE, pp. 20-29. 